\title{
Modeling of the Rate of Weight Loss in the Pyrolysis of Waste of Tobacco Stem for the Development of Charcoal Briquette
}

\author{
Suryo Purwono, Bardi Murachman, Joko Wintoko, Nur Esti Permatasari and Diah Lidyawati \\ Chemical Engineering Department, Gadjah Mada University, Jl. Grafika No. 2, Yogyakarta, Indonesia
}

Received: April 28, 2011 / Accepted: May 12, 2011 / Published: September 25, 2011.

\begin{abstract}
Waste of tobacco stem can be utilized as an energy alternative as a charcoal briquette. In the tobacco stem, there is carbon element bonded in the cellulose and can be utilized as an energy source of solid fuel. Charcoal briquette from tobacco stem can be developed via pyrolysis process. The mechanism of the weight loss due to pyrolysis reaction is an important problem and occurs in many industrial practices. The basic information that is of interest to the designer and to the operator of pyrolysis process are the conditions that cause carbonaceous materials to occur, and the effect of the fouling deposit on the transfer of heat and on the pressure drop in the flow system. The information must be related to time and system temperatures. The formation of carbonaceous material is usually to be a transient condition at least in the first stages of pyrolysis. The main objective of this paper is to find model of weight loss or reactivity of the pyrolysis process that will accurately predict gasification rate under different temperatures. This steady state kinetic study can be used to support the mathematical modeling since a suitable reaction rate expression is essential for a successful reactor model. A model of the weight loss during pyrolysis process was developed. The model developed appears to be applicable to this pyrolysis experiment for the development of charcoal briquette from the waste of tobacco stem. This can be demonstrated with the experimental data obtained from the pyrolysis processes at two different temperature. Straight lines passing through the data points for each of the samples indicate clearly that the model properly describe the pyrolysis process.
\end{abstract}

Key words: Waste of tobacco stem, pyrolysis, modelling of weight loss.

\section{Nomenclature}

$f \quad$ Fraction of sample in the reactor

$R_{T} \quad$ Reactivity or rate of pyrolysis

$W \quad$ Weight of sample in the reactor

$\theta \quad$ Time of pyrolysis

\section{Introduction}

One of the plantation as an income source in Indonesia is tobacco plantation, since there are a lot of cigarette industries in Indonesia. Up to now, there are about 160,000 ha area for tobacco plantation and the production was around 95,000 tons of tobacco leaves [1]. In the other hands, there are several negative points in the production of tobacco leave. One of them is the waste of stems of the tobacco leaves. Currently this

Corresponding author: Suryo Purwono, professor, research field: energy. E-mail: spurwono@chemeng.ugm.ac.id. waste from the cigarette industries cannot be utilized well and only small part of them were usually sold to farmer which will be converted to be organic fertilizer. Some of them is used to produce pesticide by taking the nicotine out from the stem (content of nicotine is around $2 \%$ ). In the tobacco stem, there is carbon element bonded in the cellulose and can be utilized as an energy source of solid fuel [2]. This waste can be directly burned as solid fuel. However this will create problem since there will be smoke from the combustion process and problem of the storage. This condition appear with idea to utilize this solid waste to be solid fuel which is easily handled and utilized, clean and having high calorific value. The main goal of this research is to convert tobacco stem into charcoal briquette with initial treatment to reduce nicotine 
content using extraction with several types of solvents. After extraction, then the tobacco stem was dried, grinded and then screened to get a certain mesh size. The powder then was put into an oven to release the remaining water. After that the powder was put into a retort to be pyrolyzed. The products of pyrolysis were gas, liquid and solid. The solid then was removed from the reactor and pressurized to form the charcoal briquette. Because of its importance, most research on pyrolysis of biomass has been directed toward the variables controlling the rates, mechanism and methods to minimize the liquid and gas formation. Only few papers in the literature deal with the reactivities and morphology of pyrolysis of biomass. In pyrolysis processes, there are a number of possible mechanisms of reaction and heat transfer from the sources to the solid phase. The properties and limitation of the mechanism should be known, especially if there is a resistance in transferring of heat because of the fouling particles.

The mechanism of the weight loss due to pyrolysis reaction is an important problem and occurs in many industrial practices. A number of experimental studies have been made on pyrolysis field as summarized by Albright et al. [3]. The basic information that is of interest to the designer and to the operator of pyrolysis process are the conditions that cause carbonaceous materials to occur, and the effect of the fouling deposit on the transfer of heat and on the pressure drop in the flow system. The information must be related to time and system temperatures. The formation of carbonaceous material is usually to be a transient condition at least in the first stages of pyrolysis. If the weight loss is plotted against time, a different curve may be produced depending upon the conditions. The type of curves is linear, falling rate, asymptotic and saw tooth [3]. Carbonaceous residues in the pyrolysis represent many chemical species, the common factor being representation by empirical formula $\mathrm{CH}_{n}$. Values of $n$ vary widely and Barbier et al. [4] report experimental values from 0.1 to 1.8 . The nature of the carbon varies, from polymeric deposits favoured at low temperatures to carbons produced under more extreme conditions. The morphology of carbonaceous material may also be very different. Albright et al. [5] identified seven types of carbon formed from the pyrolysis of light hydrocarbons, such as filamentous, globular and amorphous and found that the surface on which the coke deposits is a major importance in determining the properties of the coke formed. The sized of carbon aggregates deposited on the surface of the catalyst is also important since this may determine whether pore-blocking can occur.

Studies on mechanism processes were usually focused on the increasing of the deposition of thickness layer and measurement of the change of overall heat transfer coefficient, and comparing it with the original value. Little attention has been focused on the mechanisms of deposits and it is changing with time. Carbonaceous material obtained in the pyrolysis process is complex and difficult to model so the weight loss of the biomass was measured. The topic of this contribution is the measurement of weight loss during pyrolysis of waste of tobacco stem to be produced as charcoal. This is a widely used method for chars prepared from biomass.

This study was concerned with the weight loss as a function of time on stream and pyrolysis temperature. The main objective of this paper is to find model of weight loss or reactivity of the pyrolysis process that will accurately predict gasification rate under different temperatures. This steady state kinetic study can be used to support the mathematical modeling since a suitable reaction rate expression is essential for a successful reactor model.

\section{Experiment}

\subsection{Preparation Stage}

Chemical used in this research were: distilled water, benzoic acid, cuprum chloride, salt, red methyl indicator, calcium hydroxide, sodium carbonate, oxygen, and pyrogalol. Those chemical were from the laboratory. The waste of tobacco leaves was from PD Tarumartani, Yogyakarta. In the preparation stage, 
several extraction processes were done to remove the nicotine content in the waste of tobacco stem. For this process, the solvent used were ethanol, normal hexane and steam. Extraction was done by putting $1 \mathrm{~kg}$ of sample into extractor which was connected into solvent tank which consists of 5 liters solvent. The extraction was done at temperature close to the boiling point of the solvent.

\subsection{Pyrolysis Reactor}

The goal of pyrolysis of waste of cigarette industries is to get components which can be used as charcoal briquette. The temperature used for the pyrolysis process was between $250-500{ }^{\circ} \mathrm{C}$. The experimental procedures for the pyrolysis process as follows: (1) dried tobacco stem at a certain weight were put into the pyrolysis reactor and heated up to a certain temperature; (2) the product leaving the reactor was cooled down to room temperature; (3) the liquid product was collected in a flask while the gas product was put into a big bottle. The solid product was then removed from the reactor.

The reactor employed for the pyrolysis experiment consisted of a chamber having diameter of $10 \mathrm{~cm}$ and height $15 \mathrm{~cm}$ and electrically heated. The outlet was connected to a gas feed and liquid trap. The trap was functioned as crude gas cyclone, and was used to collect polymeric materials (tars) that were carried with the flowing gas. A chromel-alumel thermocouple connected to a data logger was used to measure the gas temperature. The external skin temperature was measured by a second thermocouple having a tip bent downwards. Schematic of the bench scale apparatus used to study weight loss in the pyrolysis process is given in Fig. 1.

Nitrogen was used to flush the system to remove air and undesired gas prior to each run. The reactor was heated to the desired temperature under flowing of nitrogen with the heating rate around $25^{\circ} \mathrm{C} / \mathrm{min}$.

\subsection{Proposed Model}

In general, sample weight loss with time is not uniform so the rate of pyrolysis varies with the fraction gasified. At any fraction gasified, $f$, the pyrolysis rate $R_{T}$ may be calculated in units of time ${ }^{-1}$ from the weight loss as,

$$
R_{T}=-\frac{1}{W_{0}}\left(\frac{d W}{d \theta}\right)
$$

where $W_{0}$ is the starting weight of coke, $R_{T}$ is a point value and will usually vary with $f$. The rational definition of reactivity for the coke or char sample when $R_{T}$ changes with $f$ is to use a uniformity weighted mean over the range of pyrolysis or

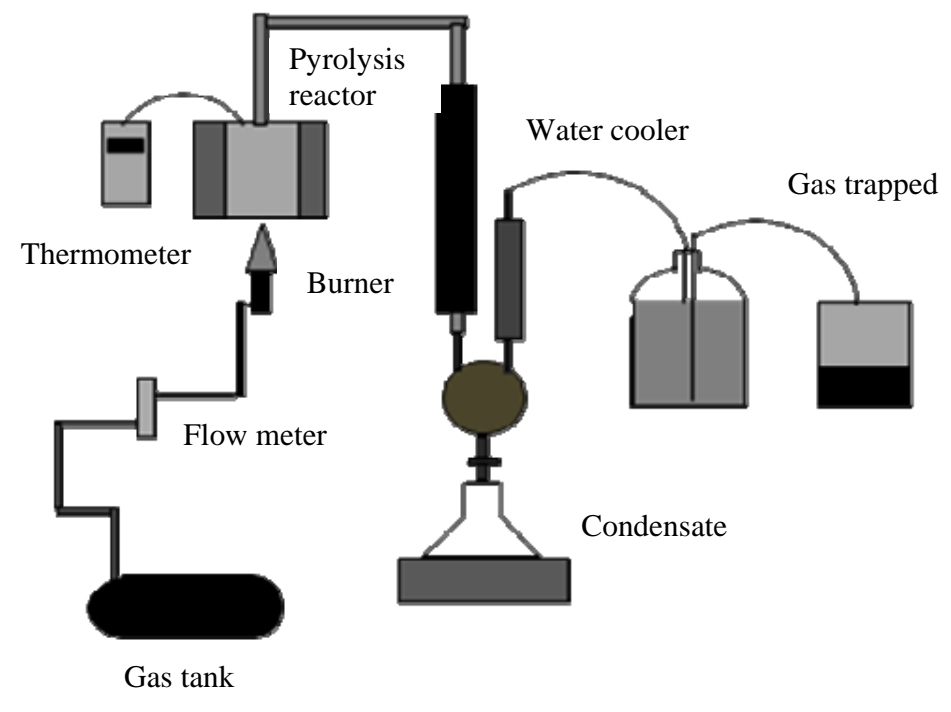

Fig. 1 Equipment for pyrolysis experiment. 


$$
\bar{R}_{T}=\frac{\int_{f_{o}}^{f t} R_{T}(f) d f}{\int_{f_{o}}^{f t} d f}
$$

where $R_{T}$ is now the sample reactivity. Note that the limits in the integral should not be zero and unity because of graphical integration problems and measurements errors near $f=1$.

An alternative is to fit the weight loss data with a model and use the model to calculate $R_{T}$ or the reactivity at a specific value of $f$, usually $f=0.5$. This alternative provides data smoothing and is more in line with current practice which generally defines sample reactivity at $f=0.5$. The fraction of gasification or weight loss is an empirical function of time and can be written as:

$$
f=1-\exp \left(-a \theta^{b}\right)
$$

or

$$
\theta=[-(1 / a) \ln (1-f)]^{1 / b}
$$

where parameters $a$ and $b$ depend on the pyrolysis condition. On substitution in Eq. (1), the rate of pyrolysis becomes

$$
R_{T}=a^{1 / b} b[-\ln (1-f)]^{(b-1) / b}(1-f)
$$

It can be seen that in this model, $R_{T}$ is a function of fractional gasification. Substituting Eq. (4) into Eq. (2) yields

$$
\bar{R}_{T}=a^{1 / b} \int_{f_{0}}^{f t}(1-f)[-\ln (1-f)]^{(b-1) / b} d f /\left(f_{t}-f_{0}\right)
$$

If reactivity is defined at $f=0.5$, then

$$
R_{T f=0.5}=0.5 a^{1 / b} b(\ln 2)^{(b-1) / b}
$$

The parameters $a$ and $b$ in Eqs. (5) and (6) can be calculated from weight loss data by least squares using the linearized form of Eq. (3)

$$
\ln [-\ln (1-f)]=\ln a+b \ln \theta
$$

\section{Results and Discussion}

\subsection{Pyrolisis Process}

In the pyrolysis experiments, the condensate formed is in the range of 25 to 45 percent of the original weight of waste of tobacco stem while the gas formed is in the range of $10 \%$ to $20 \%$. The experimental results also show that the condensate and gas formed are affected by the temperature in the reactor and the heating rate. The thermal decomposition of hydrocarbons involves a series of primary and secondary reactions leading to a complex mixture of products. Studies show that the distribution of pyrolysis products varies considerably with the pyrolysis conditions and the type of reactor used. A study by Tsai and Albright [6] reported that at least seven surface reactions occur during most industrial pyrolysis processes. These reactions include carburization of surface, coke formation on metal surfaces, oxidation and reduction of metal surfaces, sulfiding and desulfiding of metal surface, decoking operations and corrosion of the coils of pyrolysis furnaces. They also reported that surface reaction produces the following results: (1) small amounts of ethylene, other olefins and diolefins are destroyed; (2) at least some coke is produced; (3) part of the coke is gasified; (4) carburization reactions that weaken stainless steels are a factor in eventual tube failure; (5) surface roughening and corrosion occur as a result of repeated oxidizing-reducing and sulfiding-desulfiding steps; (6) coke production at metal surfaces also destroys the integrity of the metal surfaces.

Further studies show that the reaction rate of the decomposition process depends on temperature. Therefore, the pyrolysis products increase when the pyrolysis temperature increases. Further experiment shows that a lot of methane was produced from the pyrolysis of waste of tobacco stems. The study shows that the amount of gas depends on the pyrolysis process temperature. Therefore, the gas and liquid pyrolysis products increase when the pyrolysis temperature increases. According to Nurmala [7] (2000), there are four steps in the carbonization processes of wood or biomass:

(1) In the preliminary heating, the water in the wood will vaporized and the decomposition of cellulose 
occurs up to temperature of $260^{\circ} \mathrm{C}$. In this process, the distillate formed consists of acids and methanol;

(2) At temperature between $260-310{ }^{\circ} \mathrm{C}$, most of cellulose degrades intensively to form pyroligeneous liquor, gas and small amount of tar which can be used as a preservative agent;

(3) At temperature between $310-500{ }^{\circ} \mathrm{C}$, lignin dissociates to form more tar;

(4) More uncondensable gases especiaaly hydrogen were formed at temperature between $500-1,000{ }^{\circ} \mathrm{C}$. In this step, the solid product (char coal) has high purity.

\subsection{Testing of the Model}

The model developed appears to be applicable to this pyrolysis experiment for the development of charcoal briquette from the waste of tobacco stem. This can be demonstrated with the experimental data obtained from the pyrolysis processes at two different temperature. The data given in Fig. 2 have been fitted using Eq. 7. Both data points and the fitted curve are shown in Fig. 3. Straight lines passing through the data points for each of the samples indicate clearly that the model properly describe the pyrolysis process. Fig. 3 shows that straight lines can be passed through the data points for all data points for pyrolysis process more than 30 minutes. This indicates that the model proposed can be used for further modeling of pyrolysis processes in industries.

The result of further experiment using two different samples from different type of tobacco stem (long and short) also give different results on the reactivity. This is caused by the different structure and porosity of the coke obtained. The data from literature show that the structure of the carbon will give significant effect on the reactivity. Amorphous coke is produced by a sequence that starts with gas phase reactions. The acetylenic compounds and diolefins condense forming aromatics. The aromatics react producing tar molecules, then tar droplets impinge on the metal surfaces or are formed there. The droplets either wet or partially wet the solid surfaces, and finally the tar on the surface

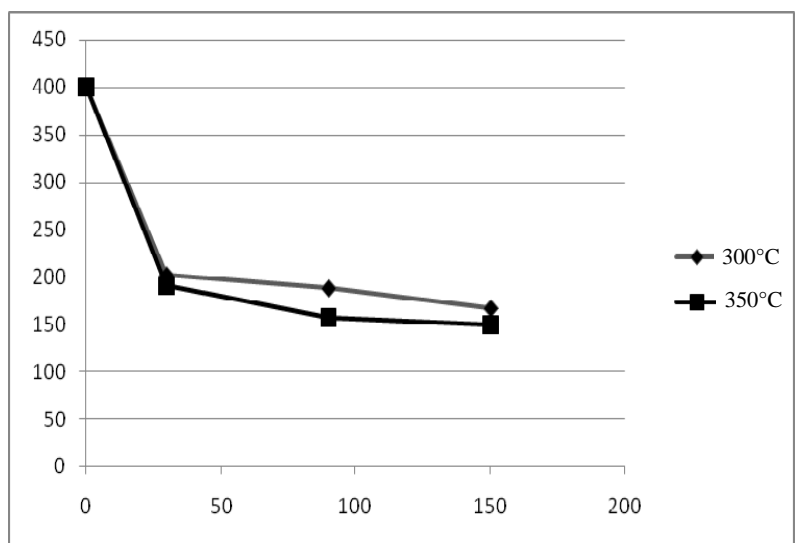

Fig. 2 Weight loss during pyrolysis process for two different temperatures.

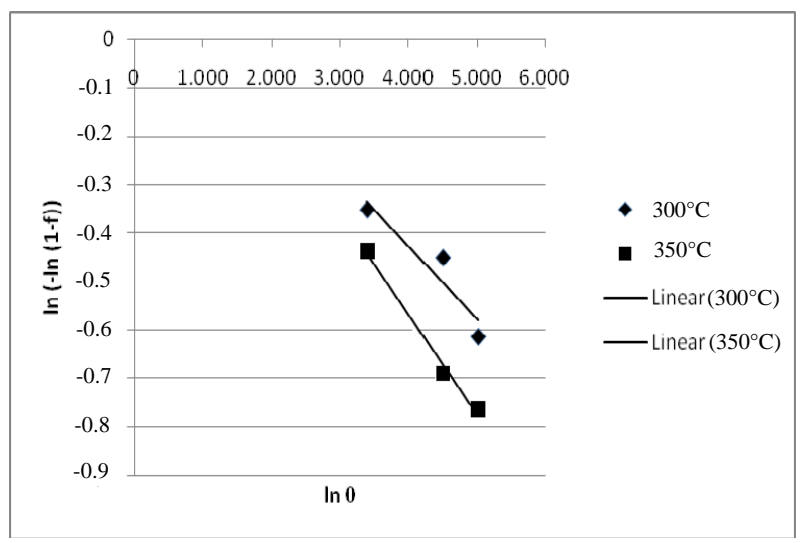

Fig. 3 Test of the proposed model.

dehydrogenates, producing carbon materials (coke). In those cases in which the droplets only partially wet the surface, the coke formed has the appearance under the scanning electron microscope of a series of partially agglomerated spheres. This coke is designated here as globular. This type of coke contains no metal particles unless it becomes mixed with surface catalyzed coke. In commercial pyrolysis furnaces, the coke appears to be primarily amorphous in character: most of it collects near the exit of the coil. In naphtha furnace, the coke is often rather uniformly distributed and frequently has a laminated character when cross sections are examined. The inner surface is generally rather shiny and contains metal particles, possibly indicating the presence of filamentous coke.

Pyrolysis temperature appears to slightly affect the weight loss [8]. The effect of temperature can be seen by plotting the linearized form of Eq. (3). Fig. 3 shows as 
the temperature increase, the changing in weight loss decrease linearly. According to Albright et al. [5], the formation of carbonaceous material at relatively low temperature is controlled by the surface catalyzed decomposition of adsorbed hydrocarbon to give atomic carbon and hydrogen. In this mechanism, atomic carbon dissolves in the metal and recrystallize on a carbon phase to form rope like structure. At higher temperatures, a different carbonaceous material formation mechanism emerges. Albright et al. [5] reported that this mechanism is complex, involving polymerization in the gas phase and condensation on the surface to give high boiling point polycyclic aromatic compounds (tars). Evidence for the emergence of the high temperature mechanism was provided by the experiments. At higher pyrolysis temperature, large amount of tars were obtained in the gas-liquid separator after $150 \mathrm{~min}$ on stream, whereas virtually only a little amount of tar was collected at relatively low pyrolysis temperature.

Statistical calculations also show that the model is an appropriate representation of the data since the coefficient of determination, $\mathrm{R}^{2}$, for all experiments is close to one.

\section{Conclusions}

The results of this investigation lead to the following conclusions: The changing of sample weight with time in the pyrolysis process can be modeled with fraction of weight loss. The model fit very well with the experimental data. It has been shown that several parameters affect the mechanism of the development of carbonaceous materials.

\section{Acknowledgments}

The authors are grateful for funding from Directorate General of Higher Education (DP2M-Dikti).

\section{References}

[1] Forestry Department, Forestry Industries in Indonesia, Jakarta, 1991.

[2] J.G. Haygreen, J.L. Bowyer, Forest Products and Wood Science: an Introduction, The Iowa State University Press, Ames, Iowa, 1982.

[3] L.F. Albright, B.L. Crynes, W.H. Corcoran, Pyrolysis Theory and Industrial Practice, Academic Press, New York, 1983, pp. 87-93.

[4] J. Barbier, E. Churin, J.M. Parera, J. Riviera, Characterization of coke by hydrogen and carbon analysis, React. Kinet. Catal. Lett. 29 (2) (1985) 323.

[5] L.F. Albright, C.F. Mc.Connell, K. Welther, Thermal hydrocarbon chemistry, Adv. Chem. Ser. 183 (1979) 210.

[6] C.H. Tsai, F.L. Albright, Industrial and Laboratory Pyrolysis, ACS Symp. Series, Washington D.C, 1976.

[7] K.T. Nurmala, Briquette from saw dust of teak wood as an alternative energy, Research Report, Chemical Engineering Department, Gadjah Mada University, Yogyakarta, 2000.

[8] J. Chatooopadhyay, C. Kim, R. Kim, D. Pak, Thermogravimetric characteristics and kinetic study of biomass co-pyrolysis with plastics, Korean Journal of Chemical Engineering 25 (5) (2008) 1047-1053. 